\section{Know Thy Users}

User Research

Techniques to

Build Empathy and

Improve Decision-

Making

\section{Amanda Etches, Guest Columnist}

Amanda Etches is Head, Discovery \& Access, University of Guelph Library in Ontario, Canada.

Correspondence concerning this column should be addressed to Eric Phetteplace, Emerging Technologies Librarian, Chesapeake College, 1000 College Circle, Wye Mills, MD 26179; email: ephetteplace@chesapeake.edu.
At the 2012 Computers in Libraries conference I was fortunate to attend a presentation by Amanda Etches where she outlined, in concise but comprehensive form, many methods of user research. The presentation struck me as something every librarian, no matter what department they work in, should be aware of. Sure, we've heard of usability testing, we've conducted a few surveys, but what do we really know of numerous methodologies for collecting data directly from the people who matter most? I hope that this column will enlighten readers as it surveys the field and offers specific examples of how libraries benefit from user research.-Editor

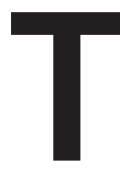

hink back to the last time you redesigned, changed, or updated something in your library. It could have been your reference desk, your website, your signage, or just about anything else, either physical or virtual. Try to remember how you made the decisions you made about whatever it is you redesigned, changed, or updated. If you work in a tiny library, maybe the decisionmaking process was as simple as just going ahead and implementing your own idea (lucky you). If you work in a large, multi-branch institution, chances are you probably struck a committee, drafted a project charter, performed a literature search, discussed a lot of opinions in a lot of committee meetings, did a focus group or two with your users, and finally wrote a report outlining your recommendations for that reference desk or homepage or sign.

If that latter scenario rings uncomfortably true to you, you're not alone. I've worked with enough libraries and talked to enough librarians to know that a lot of the time, our efforts to make changes to anything in our institutions (especially larger institutions) result in a lot of hours spent in a lot of committee meetings, that can often get bogged down in bureaucracy, personal opinions, and territory battles. A classic example (one that I am most familiar with) is the website redesign. If you've ever been involved with such a project, you know that much of your time is spent in negotiation with your colleagues over what content gets linked on the coveted global navigation, which pages should stay and which should go, where on the homepage the login button should go, and other similarly infuriating details. One redeeming quality of web development is that you usually have hard data to back you up in the form of website analytics or logs. Web analytics packages, like Google Analytics, usually run in the background of your website and tell you how many visitors visited a page, when they visited, where in the world they came from, what browser and operating system they used, and so on. Most analytics packages provide more quantitative 


\section{ACCIDENTAL TECHNOLOGIST}

data than you would ever need, but for many of us, data alone aren't enough. A common response to the argument that a certain webpage should be deleted due to lack of traffic is that, while very few people might have visited that page, it could have been the most useful page on the entire website to that handful of visitors. Fair enough.

That's where qualitative data comes in. And by qualitative data, I mean user research, because that's exactly what user research is: data gathered on user opinions and behaviors using a variety of research methods. If you're familiar with the fields of user experience design (UX), human-computer interaction (HCI), market research, design research, anthropology, or ethnography, many of these methods will be familiar to you.

\section{WHY RESEARCH USERS?}

Bringing user research data to bear on the decisions you make about your services, spaces, and interfaces elevates the discussion from one based in staff opinion to one based on the actual behavior of the people you serve: your users. If you think back to the website redesign example, it's not difficult to see how all those committee meetings that were bogged down in discussions about the color of a button could be entirely dispensed with when you bring user research into the mix. Rather than argue with your colleagues about the merits of a green button over a red one, it's a lot easier to test both buttons with a handful of users and let the results of that test inform your final decision. Moreover, doing user research provides you with a window into your users' lives, allowing you to build empathy for what they want and need to accomplish every day. With a little user research, you'd know that neither red nor green are great colors to incorporate into your web design to prompt action, because they are easily confused by colorblind people.

Those are just two small examples of the value of user research. That value multiplies exponentially the more user research data you gather.

\section{USER RESEARCH METHODS}

Once you're convinced of the value of adding user research to your regular roster of activities at work, your next step is to explore what methodologies you can use to gather that research data. The important thing to note here is that user research comes in two formal flavors and one informal one: attitudinal research, behavioral research, and participatory design.

Before launching into an exploration of each type of research and the methodologies they employ, I'd like to point out at the outset that no one method is inherently better than another. Understandably, there are occasions when finding out what your users think about something is suitable (attitudinal research); other times when exploring how they behave in a particular context provides more useful data to inform your decision-making process (behavioral research); and even other times when engaging those users in a hands-on design exercise best suits what you're trying to accomplish (participatory design). The rest of this article will explore each type of research, outline the different methodologies used in each, and provide some guidance on when to use which method to get the most out of your user research efforts.

\section{ATTITUDINAL RESEARCH}

Attitudinal research uncovers user attitudes toward things. Remember the last time you made a change in your library then did a survey to ask your users what they thought of that change? That survey is a good example of attitudinal research because it explored your users' attitudes toward the change you made. Here are some common methods you can use to gather research on your users' attitudes and opinions.

\section{Surveys}

This method likely needs little explanation. I don't know of many libraries that haven't already surveyed their users at some time to explore general customer satisfaction, gauge interest in planned or new services, resources, or events, or gather customer opinions on just about anything. Surveys can be long, involved, and broad ranging (the Association of Research Libraries survey instrument, LibQUAL+, is a good example), or they can be short and target very specific information from users. It's probably fair to say that surveys are generally quite ubiquitous in the world of library assessment, and there are countless reliable sources on how to write a good survey, so the only point I will stress here is to be careful not to make a survey something it isn't. A survey will help you gather rich data on user attitudes, not behaviors, so be sure to focus on opinions and attitudes and steer clear of questions about behavior. Why? Because behavioral data are much more reliably collected using behavioral methods.

\section{User Interviews}

Quite simply, a user interview is a one-on-one conversation with a user in an interview format, where the interviewer asks questions to help guide the conversation. User interviews are excellent follow-ups to surveys because they facilitate the allimportant "why?" affording the interviewer the opportunity to ask that question repeatedly to really explore user attitudes and opinions in some depth. Oftentimes, surveys can leave us with even more questions than answers, which is where the user interview proves to be particularly valuable, thanks to its inherently open-ended, conversational nature. I have conducted user interviews to gather user input on everything from a website redesign to a new electronic resource to an evaluation of a new service point. User interviews usually last from fifteen to sixty minutes, depending on the topic being explored, and will result in a wealth of data. If you plan on 
using this method, you would do well to secure funds for an audio recorder and the services of a transcriber-both will save you a great deal of time and effort when it comes time to synthesize interview data into a readable and actionable report.

\section{Focus Groups}

Borrowed from the world of market research, a focus group is a small gathering of users that have been brought together for a facilitated discussion on a particular topic. Focus groups usually have no more than eight participants and a facilitator who provides prompts to encourage conversation between participants. Focus group members are usually selected from the same user group or demographic to facilitate greater engagement (for example, a focus group with both students and faculty members will probably result in one of those user groups being dominated by the other). A focus group is another excellent follow-up to a survey since it also allows the facilitator to explore opinions and attitudes more deeply. One thing to watch out for in focus groups is groupthinkit's fairly easy for people in a small group to start mirroring each other's sentiments, but a good facilitator should be able to steer the group away from it. And one last point worth considering is that focus groups are a cheaper form of user interview (hear from eight people in sixty minutes compared to one in thirty-to-sixty), so keep that in mind if time and cost are a factor. If they aren't, opt for user interviews whenever you can-the data you gather from a user interview is considerably richer than the few sound bytes you'll get in a focus group.

\section{BEHAVIORAL RESEARCH}

Behavioral research tells you all about how users behave in a specific context. As the name suggests, these techniques value user behavior over user opinion, under the premise that what your users actually do can sometimes diverge quite drastically from what they say they do. The following provides an overview of the research techniques you can use to collect data and gain insight on your users' behaviors.

\section{Usability Testing}

Usability testing is probably the most instantly recognized of all the behavioral research methodologies. Usability testing is a way to test the usability of something (it could be an interface, website, service point, resource, or just about anything virtual or physical) by giving test subjects a set of tasks to complete and watching them complete those tasks, making note of everything they do in the process. In a usability test, the subject usually narrates the process he/she goes through to complete the tasks and the tester either records those behaviors with an audio/video recorder, or takes copious amounts of notes (the former costs more, the latter is easier to do). Unfortunately, usability testing is often tacked onto a design project in the late stages of the process, either right before the ship date or sometimes even after, which limits the value of this research technique. However, if you work usability testing into the design process before, during, and after the design is actually complete, you will have invaluable behavioral data to input into the design process, which can only result in a more usable finished product. Finally, remember not to assume that usability testing is just for complex software interfaces-I've gathered just as much valuable data from usability testing signage in a building as I have from usability testing a website navigation system.

\section{Contextual Inquiry}

Contextual inquiry is quite simply observing your subjects in their natural environments or contexts without interacting with them in any way. When you're new to this user research technique, you might feel awkward standing around and just watching people, but that awkwardness fades as soon as you realize that there is almost no better way to gain insight into user behavior than to just watch how people behave, make notes on those behaviors, and extrapolate patterns as a result. While there may be a temptation to consider yourself a contextual inquiry expert just by virtue of the fact that you often make deliberate observations about users in your library, it's important to not confuse the results gained from an actual contextual inquiry exercise with casual observation. The latter provides anecdotal evidence, whereas the former results from focused time, dedicated attention to the subjects, a surrendering of assumptions, rapid note-taking, and a final synthesis of data into observable patterns. As you may expect, contextual inquiry as a method is best called upon when you're investigating physical spaces and changes, such as a physical renovation, building a new service desk, investigating where to place self-check machines, and other such physical remodeling.

\section{Walk-throughs}

Take contextual inquiry, add interaction with the subject, and the result is more or less a walk-through. As the name suggests, walk-throughs are actual subject narratives where you sit down with a user and ask him/her to walk you through something specific. For example, if you are thinking about revamping the print/copy service at your library, you might ask a user to walk you through the process they go through to print something at the library. The walk-through could be physical and take the form of an actual walk through the library, or it could just be a conversation, where the user builds a narrative that starts at the beginning of the task and ends at the completion of the task. The product of a walk-through is usually a list of touchpoints (i.e. points of interaction (physical, virtual, and technological) between the subject and the Library) that your test subject has identified in the completion of the task. In our print/copy example, your subject might 


\section{ACCIDENTAL TECHNOLOGIST}

identify the following process:

- Find something online that needs to be printed

- Go to the change machine to get change for a printing card

- Go to the printing machine to buy a printing card

- Add money to the printing card

- Go to the information desk to get help printing (possibly many times during the process!)

- Go to a library computer to find the item to print

- Send the item to print

- Go to the printer and insert printing card

- Release print job

- Get print job and go home happy

Walk-throughs can be just as valuable for physical space research as they are for research on virtual habits and behaviors. The thing to keep in mind with walk-throughs is that some users are great at building narratives around tasks they need to complete and others are challenged by the prospect, so the data you gather might be spotty depending on your subjects. Done right, a walk-through exercise can help you identify all the touchpoints and zero in on the pain points your users have to deal with to get something specific done at your library.

\section{Journey Maps}

A journey map can be the product of a physical walk-through. Journey maps outline the actual path a subject will take to accomplish something in your building in a graphical way, usually on a blank floor plan. In the earlier example of the print/copy service, where your user listed all the touchpoints he or she went through to successfully complete the printing task, a journey map would take those touchpoints and plot them graphically on a map. Journey maps are a great way to visualize the physical journeys your users have to undertake to get things done in your building and usually result in small changes that can improve that experience (e.g. move the change machine closer to the printing card machine!).

\section{Cultural Probes}

Not nearly as uncomfortable as it sounds, a cultural probe is a way to collect narratives from users over extended periods of time. Cultural probes are classic ethnographic methods where test subjects use specified tools to tell stories about some aspect of their lives. The tools most often used in cultural probe research are things like diaries or journals, cameras, both still and video, and increasingly, social media tools like Twitter, Tumblr, Flickr, and YouTube to document their behavior when performing a specific activity. In Studying Students: The Undergraduate Research Project at the University of Rochester, Judi Briden discusses how the research team provided students with disposable cameras and asked them to photograph twenty specific things. The resulting images captured by eight students provided a trove of rich data that the team admits could not have been captured any other way. ${ }^{1}$

\section{PARTICIPATORY DESIGN}

Participatory design is a loosely defined series of techniques that both encourage user participation in the design of things, while also shedding light on their preferences and behaviors in the process. As you might imagine, participatory design is a wide-open field that includes any activity where you engage your users in helping you come up with the design of something (a space, service, interface, or anything else), not just ask them what they think about it or how they would engage with it. The following highlights some common and easy-to-implement participatory design techniques.

\section{Card Sorts}

A card sort is an exercise that gets to the heart of how a user categorizes a specific series of information and, by extension, how that same user might search for that information within a broader context. For example, if you are developing a new navigation system for your website, you would do well to engage your users in a couple of card sorting exercises. Start with an open card sort where you write down each navigation item on a single card (index cards work best), then hand the series of cards to a user and ask him/her to organize those cards into categories that make sense to them. Finish the exercise by handing them blank cards and asking them to name each category they've come up with. This exercise provides invaluable insight into how your users will search and browse for content on your website, what pieces of information they will put together (e.g. they will probably put hours and location info into a single category), and what trigger words they will look for to get them to the information they need.

When you're close to nailing down your new navigation scheme, perform a closed card sort where you use two series of cards (one series for your navigation items, one for your navigation categories), asking your users to sort the navigation items under the category that makes sense to them. This is a good way to do some final testing before launch to make sure you've got it right.

While card sorts work particularly well for testing web navigation schemes, they can work equally well for organizing/categorizing anything, from a series of directional signs in your library to a phone menu.

\section{Cognitive Maps}

Cognitive mapping is a useful design process where you ask users to draw a map of a physical or virtual space in an attempt to understand how they navigate that space to complete a task. Particularly useful for library building and renovation projects, having users complete a cognitive map of various service points in your library can provide valuable 
insight into how your physical environment enables them to accomplish tasks and where and when your physical environment actually puts up barriers to accomplishing those tasks. A cognitive mapping exercise can be particularly enlightening when done with users with disabilities.

\section{Rapid Prototypes}

Rapid prototyping is a design technique you can use to come up with and test design concepts quickly and affordably. As a participatory design technique, rapid prototyping actually involves users in the design exercise, usually allowing them the latitude to dream big and imagine a best-case scenario with no constraints. In Studying Students, Nancy Fried Foster and Susan Gibbons discuss a few ways in which the team at Rochester engaged students in the space redesign process by inviting them to draw their ideal space with poster board, markers, and other supplies provided by the team. ${ }^{2}$ While such a rapid prototyping exercise won't result in actual designs and floor plans you can hand off to your contractor, they do provide a way to involve your users in the design process and will shed light on what's important to them (which you can then roll into your actual redesign plans).

\section{Reverse Guided Tours}

Most of us give guided tours of our spaces to our new users all the time. What if we turned those tables and invited our users to give us tours of library spaces instead? I'd bet such a tour would be thoroughly enlightening! Despite our best intentions for the use of our physical spaces, our users usually figure out ways to make those spaces work best for them, whether it's moving furniture to accommodate their needs, to sitting on the floor when there's a free table nearby. In a reverse guided tour, you would encourage users to be candid about what they do to make library spaces, furniture, services (or anything else) work for them.

\section{... And Everything Else}

Just about any design exercise you do where you invite your users to participate in the process (beyond giving you an opinion or telling you how they would use it) could be considered participatory design. Get creative-the possibilities are limited only by your imagination!

\section{SOME FINAL THOUGHTS}

Stepping into the world of user research opens up all sorts of possibilities, about which you are likely either thrilled or overwhelmed. Whether you see these techniques as opportunities, or you are daunted and don't know where to start, I offer the following bits of advise to get you on your way.

Start with what you want to know. Don't choose to do a card sort or a cognitive mapping exercise because you like the sound of them. Start by looking at the projects you have on the go right now or are coming up soon. Figure out what you want to know from or about your users that will help you (do you want their opinions on something? Do you need to know how they will use something? Do you want to engage them in the design process?) and pick a method that will get you the data you need.

When in doubt, explore behaviors. User experience design, as a discipline, values behavioral research above attitudinal research. Why? Three crucial reasons: (1) as I mentioned earlier, people often say one thing and do something completely different; (2) most people tend to politeness when asked something. If you ask a user if they will use a new resource or service, they will probably say yes, because they don't want to hurt your feelings. This is not only useless to you, but may actually result in poor outcomes if you value user opinion too highly when making decisions; and (3) understanding user behavior allows you to build empathy for your users, which can only result in better library services, resources, and spaces.

Triangulate. For most projects, you are probably best off using at least two (ideally, three) user research techniques to give you a good, all-round sense of your users. Think of it as triangulation. It's easier to trust the veracity of your data if you use multiple methods to collect that data. While user research deals in qualitative, not quantitative data, it's still a good idea to use multiple methods so the resulting picture you have of your users is well rounded.

Jesse James Garrett, one of the fathers of the field of user experience design and founding partner of UX design agency Adaptive Path, said, "to understand what our users need, we first have to get a sense of who they are." I hope these user research techniques provide you with a practical and useful toolkit for how to do just that at your library.

\section{References}

1. Judi Briden, "Photo Surveys: Eliciting More Than You Knew to Ask For," in Studying Students, The Undergraduate Research Project at the University of Rochester, ed. Nancy Fried Foster and Susan Gibbons (Chicago: ACRL, 2007), 47.

2. Susan Gibbons and Nancy Fried Foster, "Library Design and Ethnography," in Studying Students, The Undergraduate Research Project at the University of Rochester, ed. Nancy Fried Foster and Susan Gibbons (Chicago: ACRL, 2007), 22.

3. Jesse James Garrett, The Elements of User Experience (New York: AIGA New Riders, 2002), 51 